Article

\title{
Treatment of Effluents from the Textile Industry through Polyethersulfone Membranes
}

\author{
Rodholfo da Silva Barbosa Ferreira*D, Aline Florindo Salviano, Sandriely Sonaly Lima Oliveira, \\ Edcleide Maria Araújo $\mathbb{D}$, Vanessa da Nóbrega Medeiros $\mathbb{D}$ and Hélio de Lucena Lira
}

Materials Engineering Department, Membrane Development Laboratory, Federal University of Campina Grande-UFCG, Campina Grande, Paraiba, 58429-104, Brazil; alinefsalviano@gmail.com (A.F.S.); sandriely_sonaly@hotmail.com (S.S.L.O.); edcleide.araujo@ufcg.edu.br (E.M.A.); vanismedeiros@gmail.com (V.d.N.M.); helio.lira@ufcg.edu.br (H.d.L.L.)

* Correspondence: rodholfoferreira@gmail.com

Received: 22 October 2019; Accepted: 27 November 2019; Published: 1 December 2019

\begin{abstract}
Membranes have been widely used in the treatment of industrial effluents. However, there are still some limitations in the separation and permeability with respect to these effluents. Therefore, this study investigated the addition of $1 \%$ and $5 \%$ of an inorganic filler (clay) in polyethersulfone polymer membranes. By contact angle analysis, it was observed that the clay influenced the hydrophilicity of the membrane. The presence of the clay had an important role in the morphology of the membrane, modifying and favoring a greater quantity of pores and macropores for the porous support. For the tensile test, it was seen that the high clay content decreased the membranes properties. The flow tests, having a flow stabilized around $300 \mathrm{~L} / \mathrm{h} \cdot \mathrm{m}^{2}$ for membranes containing clay, evidenced the efficiency of the membrane for the treatment of indigo blue, representing a 200\% increase in relation to polyethersulfone membrane. The membrane containing $1 \%$ of clay presented the highest level of rejection to the effluent, around $94.0 \%$. Thus, it was evident that the addition of montmorillonite clay modified the membrane structure contributing to a higher selectivity and permeability.
\end{abstract}

Keywords: polymer membranes; polyethersulfone; industrial effluents treatment; indigo blue

\section{Introduction}

The world has turned to the process of membrane separation due to its benefits to industrial processes. The advantages of membrane separation include its low energy consumption, high efficiency in separation with its selective permeation, and non-thermal processing of sensitive composite products $[1,2]$. In this context, membranes play an extremely important role, especially in the field of water and sewage treatment [3]. Membranes have played an important role in the textile industry systems, especially in the treatment of effluents from the dyeing process where the amount of dye is present in a high percentage [4]. Thus, the membranes help in the reuse of process water from a cheap technology and simple operation.

The type of material, method of manufacture, and the configurations of the membrane modules determine both the application and the efficiency in the separation process from the hydrophilicity, permeability, and anti-fouling properties of the membrane [5]. Due to the search for excellent properties, polymeric membranes have assumed an important function in the production and the application in the process of separation by membranes [6]. Therefore, several polymers have been prominent in the manufacture of membranes, such as polyethersulfone (PES), polysulfone (PSU), and polyamide, polyvinylidene fluoride (PVDF) [7].

Among the polymers, polyethersulfone stands out as a special engineering plastic. It has many advantages, such as its high mechanical property and temperature distortion of heat, good resistance 
to thermal aging and environmental resistance, and easy processing. It has become an important material for the production of membranes with excellent separation properties, but its hydrophobicity controlled by the PES structure leads to a low membrane flux and low antifouling property, which has great effect on its application and shelf life [8-10].

Due to these weak properties, inorganic materials have been added to the polymer matrix for the production of membranes [10]. Among them, we can highlight $\mathrm{SiO}_{2}, \mathrm{Al}_{2} \mathrm{O}_{3}, \mathrm{TiO}_{2}, \mathrm{Fe}_{3} \mathrm{O}_{4}$. Clay minerals have been widely used for the manufacture of polymer/clay nanocomposites because of their hydrophilic nature, as well as their low cost and good dispersion properties in the polymer matrix [11]. Therefore, the incorporation of these materials is an effective method to improve mechanical strength and membrane porosity [12].

Recently, several studies have shown that the use of clay minerals helps in improving the properties of polymer membranes. Mierzwa et al. [13] studied the influence of clay nanoparticles on the morphology and performance of PES membranes, showing that permeability increased with the addition of clay. Simona et al. [12] produced polyethersulfone membranes modified with montmorillonite, where they had greater water absorption capacity and increased separation efficiency. Hosseini et al. [11] added montmorillonite to chitosan/poly (vinyl alcohol) (PVA) membranes. In addition to improving membrane properties, the clay increased the adsorption for removal of the studied dye, improving the resistance to membrane fouling. In most studies carried out with the addition of mineral fillers in the PES matrix, it was found that modified clays were added, which added more cost to the process.

Thus, this research aimed to produce membranes of polyethersulfone/natural clay in order to modify the polymer morphology to have better permeability and selectivity properties, thus obtaining efficient membranes for application in the treatment of effluents from the textile industry.

\section{Materials and Methods}

\subsection{Materials}

The membranes were prepared using: Polyethersulfone (PES), under the tradename Veradel ${ }^{\circledR}$ 3000P, supplied by Solvay; the Brasgel PA clay, called MMT (montmorillonite), supplied by Bentonit União Nordeste (BUN), Campina Grande-PB; the solvent N,N-Dimethylformamide P.A./ACS (DMF); and the viscosity additive poly (vinyl pyrrolidone)—PVP, (C6H9NO)n, produced by Labsynth Ltda.

\subsection{Membranes Preparation}

Initially, the solution was obtained with the pure polymer (PES), where a solution containing the polymer, viscosifying additive (PVP), and the solvent was prepared. This solution remained for $1 \mathrm{~h}$ under a stirring speed of $1000 \mathrm{rpm}$. For the polymeric solutions containing clay, dispersions with $1 \%$ and $5 \%$ of clay and solvent were produced, remaining under agitation for $30 \mathrm{~min}$ at 1000 $\mathrm{rpm}$. Subsequently, polyethersulfone and PVP were added, stirring for $1 \mathrm{~h}$. After the solutions were prepared, they were allowed to stand for $24 \mathrm{~h}$ to stabilize the solution. Table 1 shows the proportions used for the production of the membranes.

Table 1. Percentages used to obtain membranes.

\begin{tabular}{ccccc}
\hline Sample & Solvent (\%) & Polymer (\%) & Clay (\%) & PVP (\%) \\
\hline Pure PES & 80 & 15 & 0 & 5 \\
PES + MMT 1\% & 80 & 14 & 1 & 5 \\
PES + MMT 5\% & 80 & 10 & 5 & 5 \\
\hline
\end{tabular}

With the solutions prepared, they were put on a glass plate and spread by a glass stick. Thereafter, the plate was immediately placed in a nonsolvent bath (distilled water) at room temperature until the membrane was completely precipitated. 


\subsection{Characterizations}

The contact angle analyzes were performed by the sessile drop method through a portable contact angle (Phoenix-i of the Surface Electro Optics-SEO). The drop was manually formed by a micrometer doser and the drop image was captured by the camera built into the equipment.

The scanning electron microscope (SSX 550, Superscan-Shimadzu, Kyoto, Japan) and the atomic force microscope (AFM; SPM 9700-Shimadzu, Kyoto, Japan) were used to perform the morphological analysis of the membranes produced.

The surface topography and the relative surface roughness of the prepared membranes were examined using atomic force microscopy, using the dynamic mode at a scan rate of $1 \mathrm{~Hz}$. The membranes were fixed to on a support and visualized in a $1.33 \mu \mathrm{m} \times 1.33 \mu \mathrm{m}$ and analyzed by the SPM Manager program. These topographic images were used to calculate the membrane roughness of the area "Ra", the area roughness average, which can be calculated from the following Equation (1).

$$
R a=\frac{1}{L_{x} L_{y}} \int_{0}^{L y} \int_{0}^{L x}|f(x, y)| d x d y
$$

The tensile tests on the membranes were performed with a load of $196 \mathrm{~N}$ at a rate of $5.0 \mathrm{~mm} / \mathrm{min}$ (EMIC DL 2000-Instron, São José dos Pinhais, Brazil). The tests were conducted at room temperature according to ASTM D 882 standard [14].

The flow measurement tests (distilled water and indigo blue) were performed in a perpendicular filtration cell (Figure 1). The membranes were tested under pressures of 1 and 1.5 bar. For the effluent test, a solution containing 500 ppm indigo blue was prepared. To calculate the rejection, five samples of the permeate obtained in the flow measurement were collected. The collected permeate analyzes were done in a spectrophotometer-UV BEL SP 2000 (BEL Engineering, Monza, Italy).

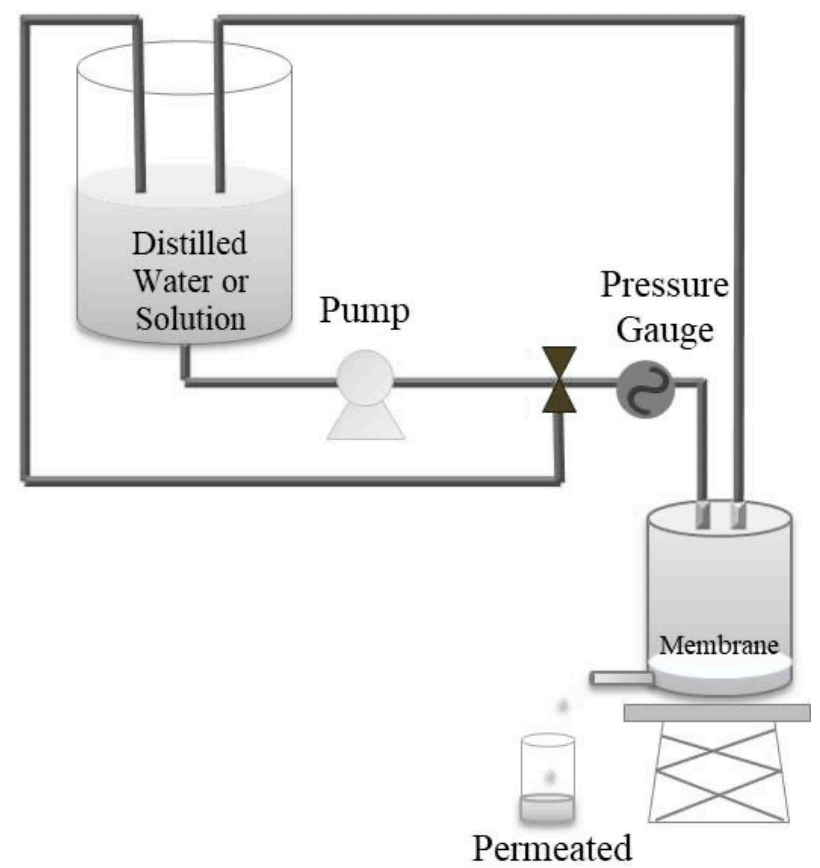

Figure 1. Flow measurement system. 


\section{Results and Discussion}

\subsection{Effect of Clay on Membrane Hydrophilicity}

Figure 2 shows the contact angle results for the membranes produced. This analysis allowed evaluation of the qualitative and quantitative characteristics of the membrane surface on the liquid used. It was possible to observe that for all membranes, the contact angle $(\theta)$ was less than $90^{\circ}$, characterizing the surface as hydrophilic. Despite the hydrophilicity of the PES membrane, the addition of clay increased it in the membrane surface, being higher for the membranes containing $5 \%$ clay.

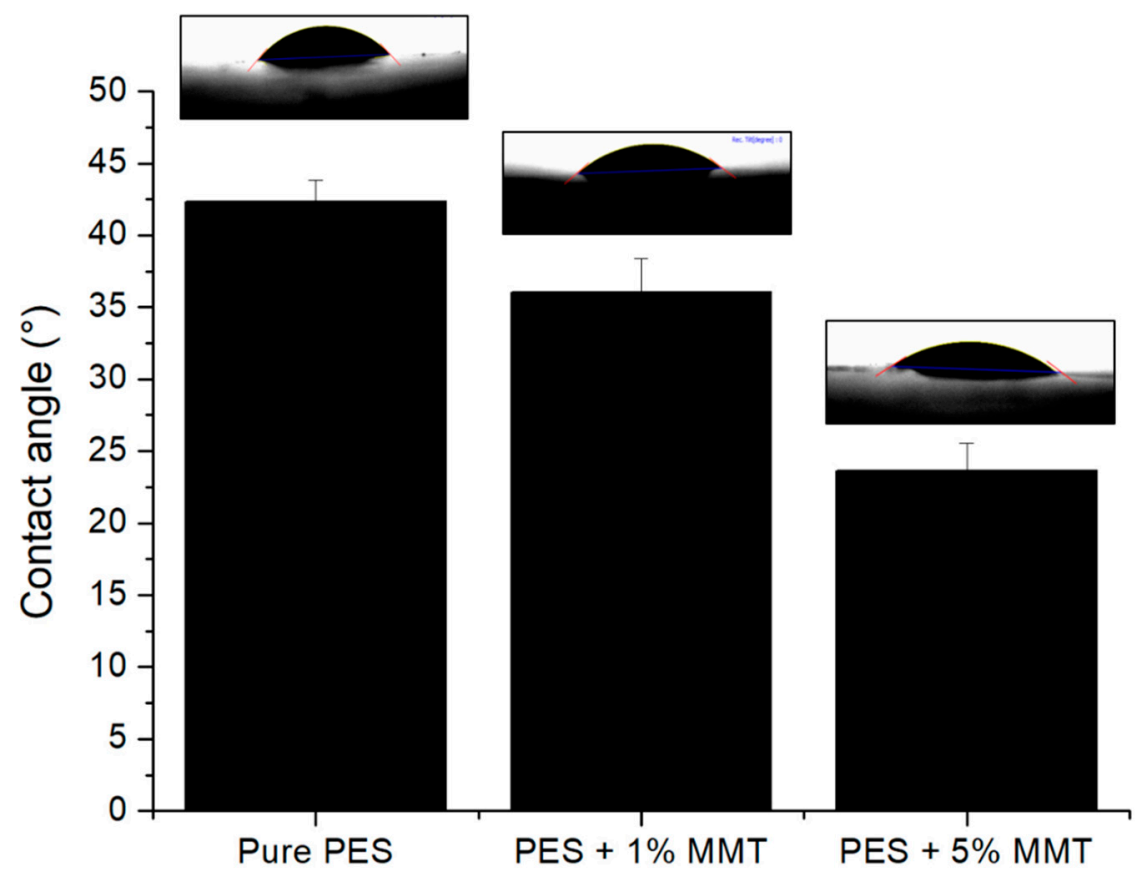

Figure 2. Surface of contact angle of polyethersulfone (PES) membranes with different concentrations of montmorillonite (MMT).

The addition of clay, which is hydrophilic, gives the membrane surface this characteristic $[15,16]$. This aspect increases the permeability of the membrane with the improvement of the anti-fouling, consequently providing an excellent performance for these materials [2,15]. These variations of hydrophilicity may occur due to the migration of the clay nanoparticles to the membrane surface $[2,17]$. Increasing the percentage of clay may cause a decrease in membrane permeability by blocking the pores [16].

\subsection{Membrane Morphology}

Figure 3 shows SEM photomicrographs of flat membranes. It is seen that the membranes apparently showed a surface without pores for all the membranes, and the ones containing clay obtained a greater roughness at the surface, since the addition of hydrophilic nanoparticles changes the kinetics and the thermodynamics of the process of phases inversion, which leads to different morphologies [2]. Although SEM images do not allow the pore sizes to be visualized on the membrane surface, probably because of the coverage made with the metallization, it was verified from the cross-section images that the pores diminished from the base to the top of the membrane until they reached pores in the micropore range. This observation can be confirmed by the AFM images (Figure 4). 

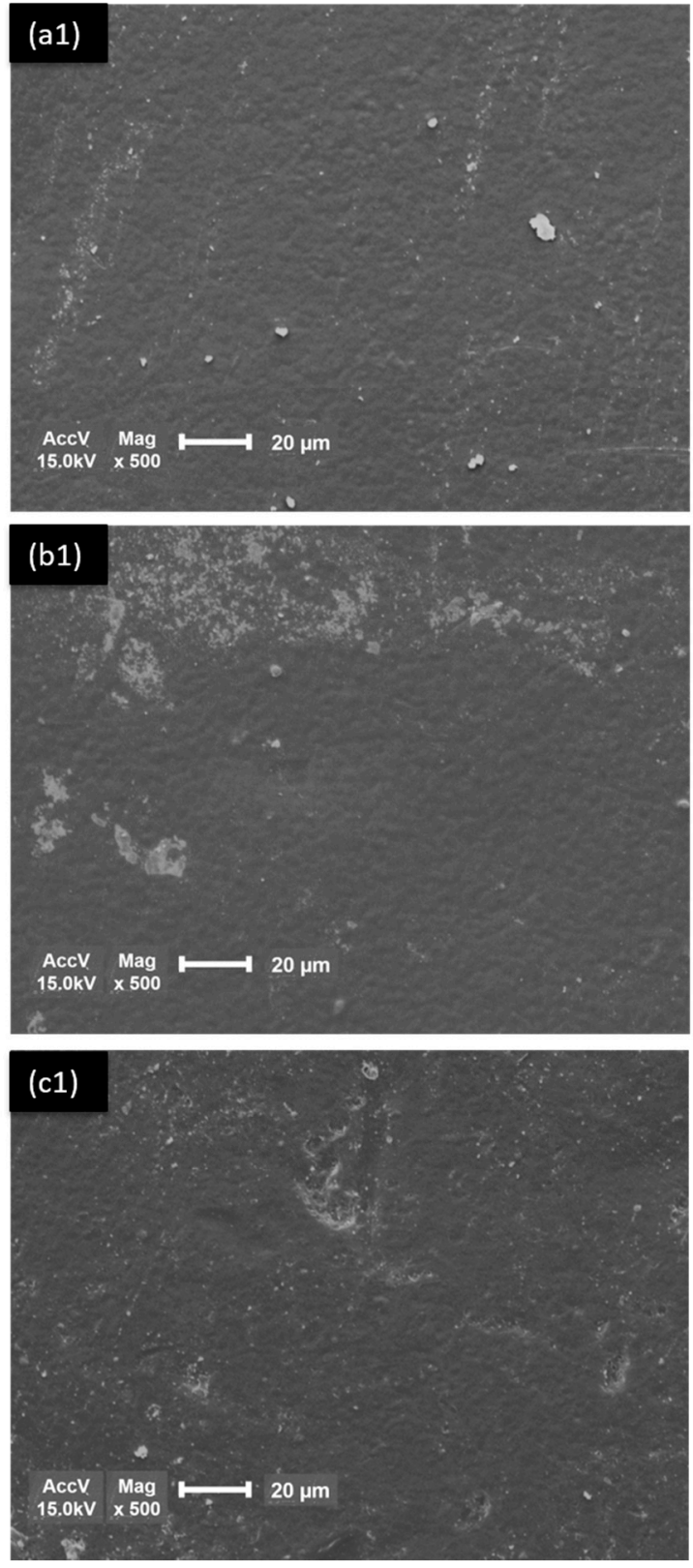

Figure 3. SEM photomicrographs of membranes with different clay contents: (a1,a2) Pure PES, (b1,b2) $1 \mathrm{wt} \% \mathrm{MMT}$, and (c1,c2) $5 \mathrm{wt} \%$ MMT.

According to Figure $3(\mathrm{~b} 2, \mathrm{c} 2)$, the addition of clay led to a decrease in the filtering skin attached to the membrane porous support, increasing the porosity of the support as compared to the pure PES membranes. This phenomenon was also observed by the authors in [18-20]. The increase in porosity is due to the clay acting as a porogenic agent together with the PVP in the membrane formation, obtaining a uniform porous morphology [21,22]. They also presented a greater number of fingers in every cross-section, where they are characteristic of PES membranes [23]. This happens due to the contact of the membrane with nonsolvent bath, occurring the spinodal decomposition with localized stresses [24].

A decrease was observed in the filtering skin of the polyethersulfone membranes. The PES membrane obtained a thickness around $1.50 \mu \mathrm{m}$, but with the addition of $1 \%$ and $5 \%$ montmorillonite, the thickness decreased to $0.89 \mu \mathrm{m}$ and $1.03 \mu \mathrm{m}$, respectively. This phenomenon occurs because the clay acts accelerating the precipitation of the membrane, thus bringing a thinner filtering skin along the cross-section of the membrane, leading to better flow results. 

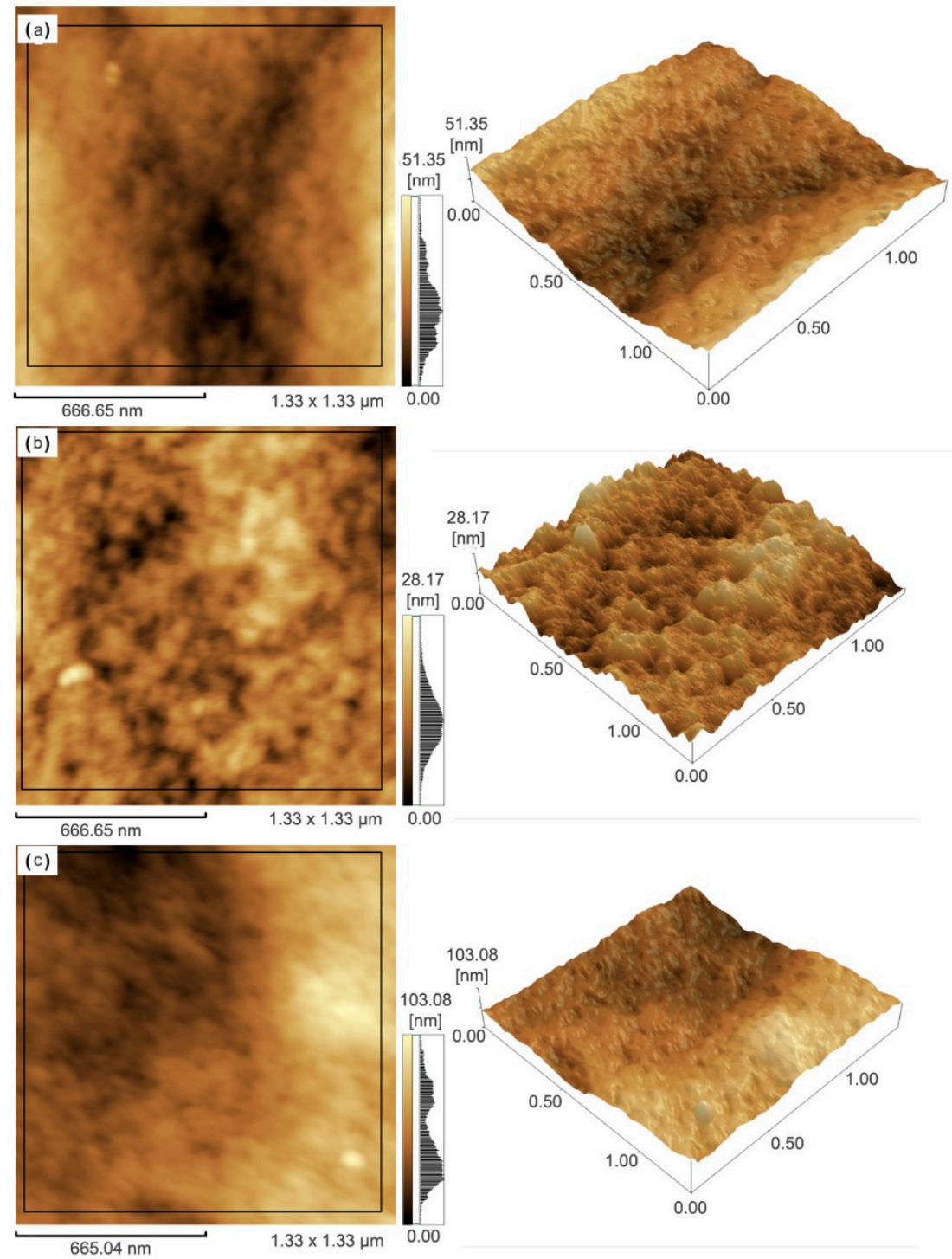

Figure 4. The surface AFM images of the membranes: (a) Pure PES, (b) PES + 1\% MMT, and (c) PES + $5 \%$ MMT.

The presence of different loadings of clay on membrane could also alter the surface morphology. One of the key parameters closely related to the antifouling ability of the membranes is membrane roughness. AFM was used to investigate the variations in surface morphology in these conditions. Figure 4 shows the AFM 3D-surface and phase images with size of $1.33 \mu \mathrm{m} \times 1.33 \mu \mathrm{m}$ and the roughness parameters are reported in Table 2.

Table 2. Surface roughness parameters of the PES and PES/clay membranes.

\begin{tabular}{cccc}
\hline Membrane & Ra $(\mathbf{n m})$ & Rz $(\mathbf{n m})$ & Rzjis $(\mathbf{n m})$ \\
\hline Pure PES & 3.219 & 28.126 & 13.742 \\
PES + MMT 1\% & 4.108 & 40.77 & 20.191 \\
PES + MMT 5\% & 9.401 & 63.593 & 31.533 \\
\hline
\end{tabular}

The membrane surfaces are presented by two distinctive regions: Bright and dark regions. Dark regions correspond to low height areas/valleys/pores and bright regions to the highest areas. More ups and downs could result in the higher roughness of the membrane surface, which could be regarded 
as a sign of the enhancement of the surface pore diameter based on the surface topography of the membranes shown in Figure 4.

To provide more details, the membranes surface roughness parameters were calculated and are presented in Table 2, where $\mathrm{Ra}$ is the arithmetic mean roughness, $\mathrm{Rz}$ is the maximum height, and Rzjis is the 10-point mean roughness. The results showed that all membranes roughness parameters with the addition of clay were larger than those of the pure PES membrane. Similar results were also reported by different authors [25-29]. By adding the hydrophilic nanoparticles to the casting solution, it was observed that the mixed matrix membranes had high surface roughness in comparison to the pure membranes.

The clay tended to protrude at PES membrane surface during coagulation. It also caused the polymer solidification near the surface, so large local peaks were formed. It is worth noting that when clay reached the membrane surface, depending on the thermodynamic condition during phase inversion, the amount of roughness tended to increase. Moreover, disturbing the homogeneity of the polymeric chain on the surface may be another reason for the high roughness value in the blended membranes. Consequently, the high roughness could be attributed to the increase in efficient area for filtration, resulting an increment in permeability and membrane fouling mitigation [30].

This section is divided by subheadings to provide a concise and precise description of the experimental results and their interpretation, as well as the experimental conclusions that can be drawn.

\subsection{Tensile Strength}

The tensile strength and elongation at break for the membranes studied are shown in Figure 5. From the analysis, the incorporation of clay increased both properties for membranes containing $1 \%$ MMT with values of $6.73 \mathrm{MPa}$ and $37.34 \%$. The higher aspect ratio of the clay particles can cause an exfoliation among the PES polymer chains, thus providing a better interaction between the membrane surface and the porous support [31,32].

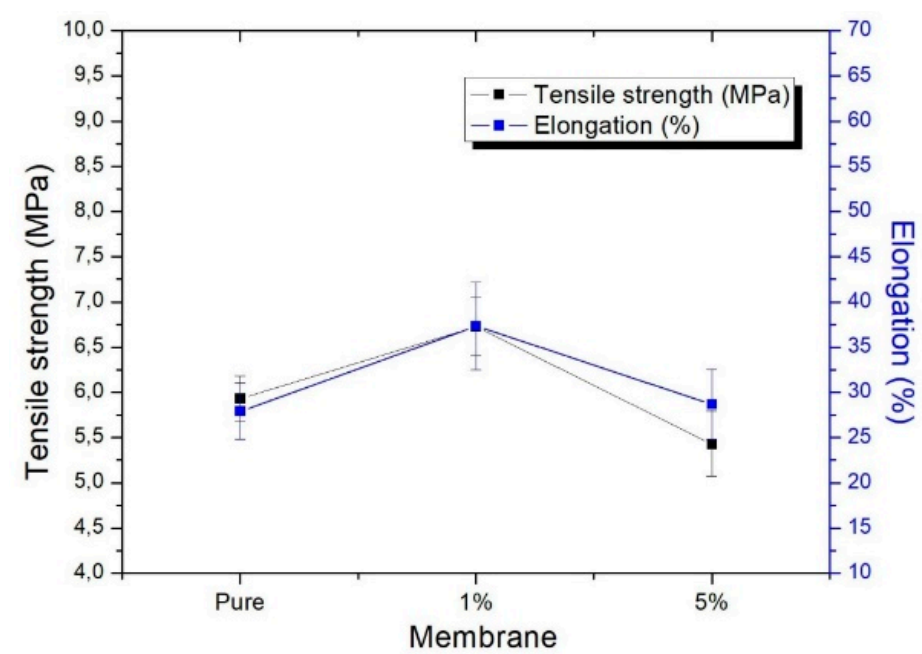

Figure 5. Traction test for PES membranes with different concentrations of MMT.

With the percentage of $5 \% \mathrm{MMT}$, there was a decrease in values, presenting values of $5.43 \mathrm{MPa}$ and $28.67 \%$. The high increase of the clay concentration resulted in the reduction of the mechanical properties due to the change in the porous membrane support morphology. As can be seen in Figure 3(c2), the membrane presented a large number of fingers and macropores in every porous support, so they may have negatively influenced the mechanical properties to membrane with $5 \%$ MMT. This behavior was also observed by Muhamad et al. [33]. 


\subsection{Membrane Flow Properties and Efficiency}

Figures 6 and 7 illustrate the water and indigo blue mass flow measurement tests, respectively, for the membranes produced. The membranes were tested for pressures of $1.0 \mathrm{bar}$ and $1.5 \mathrm{bar}$. The indigo blue solution was prepared containing $500 \mathrm{ppm}$. Figure $7 \mathrm{c}$ represents the indigo blue and the permeate collected in the flow analysis.
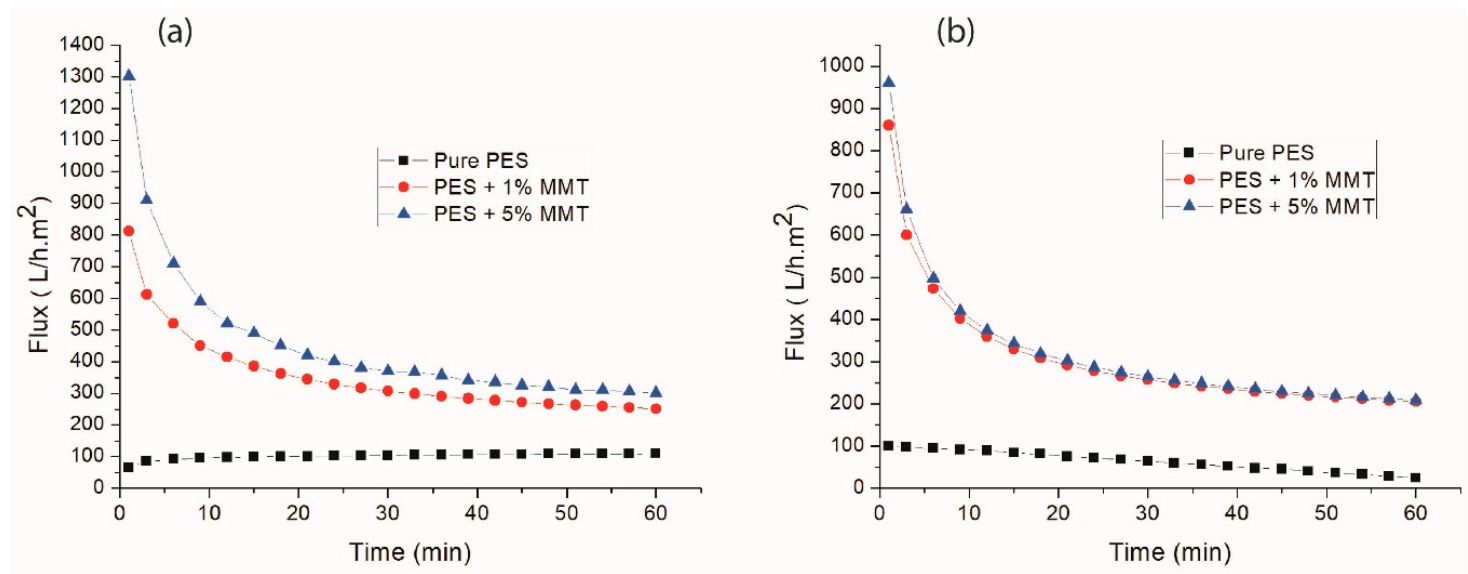

Figure 6. Flow test with distilled water for PES membranes with different concentrations of MMT (a) 1.0 bar and (b) 1.5 bar.
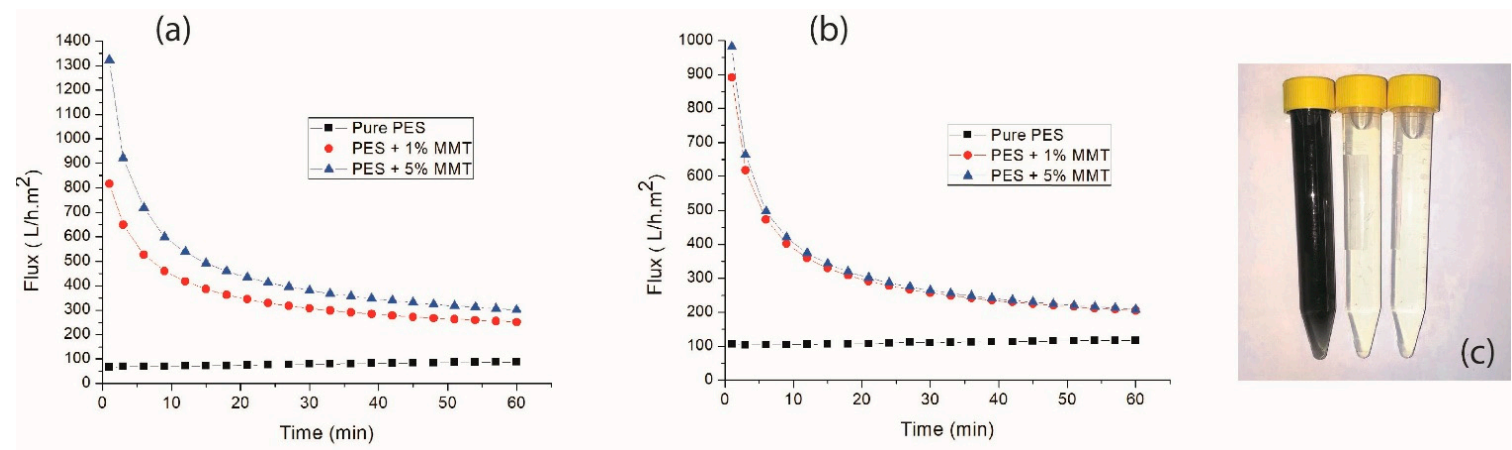

Figure 7. Indigo blue flow test for PES membranes with different concentrations of MMT (a) 1.0 bar, (b) 1.5 bar and (c) emulsion with indigo blue and collected permeate.

The flow curves were similar for two studied effluents. The effluents tended to decay throughout the test, which can be attributed to hydration or membrane fouling. The flow started to stabilize in approximately $60 \mathrm{~min}$ of assay, excluding the Pure PES membrane, which began the assay practically stabilized. This can be done from the hydrophilicity of PES, as seen by contact angle and also from the mechanical compaction promoted by the applied pressure, decreasing the membrane permeability [34]. The membranes containing 5\% MMT obtained a higher flux, which can be attributed to the interaction between polymer/clay/solvent and the morphology of the membrane, from a larger number of pores and macropores in the porous support of the membrane, as well as a smaller thickness of the filter layer [19]. Additional characteristics of this higher permeability included the hydrophilic nature of the clay, thickness of the filtering skin layer, porosity, and tortuosity. These factors have been shown to provide greater membrane efficiency [23].

In the indigo flow (Figure 7), the fouling phenomenon did not appear, which was expected because the fluid used composed solids, which could adhere to the pores of the membrane and preclude a favorable flow when compared to of water. This only shows the efficiency of the membrane for this type of effluent. The pressure obtained the highest flow for both tests was the pressure of 1.0 bar. This can be attributed to greater pore compression at 1.5-bar pressure, as well as the increased fouling of indigo particles in the membrane pores. 
Table 3 shows the yield values for the indigo blue flow test. In general, the yield increased when a higher pressure was applied to the test, with the exception of the membrane containing $5 \%$ MMT, where the yield fell by approximately $5.55 \%$, probably due to the mechanical compaction caused by the increase in pressure. The membrane that presented the highest rejection was the PES $+1 \%$ MMT at 1.5-bar pressure. Rejection was $94.0 \%$, thus showing the membrane efficiency for this type of effluent. In addition, although rejection was a little lower for the other membranes, the obtained results were satisfactory. These high rejections were probably due to the effects of combining size exclusion along with electrostatic repulsion, which plays a critical role in effecting dye separation for the membranes under study [23]. Solutes and dyes may form dimers in water, where trimers, tetramers and other aggregates may form due to the agglomeration of dye dimers in a gradual manner. The association is caused by the amphiphilic nature of the dye solutes and can be influenced by both the structure and the different physical and chemical effects of the dye [35]. From the high rejection values, especially for the PES + 1\% MMT membrane, it can be inferred that this membrane had pores smaller than 1.5 microns, considering that the average particle sizes of indigo blue suspension are in this size range, as observed by Lima et al. [36].

Table 3. Stabilized flux and rejection of the indigo blue for the membranes produced.

\begin{tabular}{ccccc}
\hline Membrane & Flux $\mathbf{( L / h \cdot \mathbf { m } ^ { \mathbf { 2 } } ) \mathbf { 1 . 0 } \text { bar }}$ & Rejection $\mathbf{( \% )}$ & Flux $\left.\mathbf{( L / h} \cdot \mathbf{m}^{\mathbf{2}}\right) \mathbf{1 . 5}$ bar & Rejection $\mathbf{( \% )}$ \\
\hline Pure PES & $88.0 \pm 1.15$ & $83.0 \pm 1.22$ & $114.0 \pm 0.84$ & $89.0 \pm 0.95$ \\
PES + MMT 1\% & $251.0 \pm 0.92$ & $89.0 \pm 1.10$ & $203.5 \pm 1.75$ & $94.0 \pm 1.50$ \\
PES + MMT 5\% & $298.5 \pm 1.03$ & $89.0 \pm 1.90$ & $203.5 \pm 1.60$ & $83.0 \pm 2.05$ \\
\hline
\end{tabular}

\section{Conclusions}

In this study, the addition of the presence of clay to polyethersulfone membranes for the effluents treatment from the textile industry was investigated. In general, the addition of clay provided a morphological modification in the membranes, resulting in a structure with pores, macropores, and fingers throughout the porous support. The modification occurred by accelerating the precipitation of the membrane, thus bringing a change in morphology. This modification caused the membrane to present a higher hydrophilicity with greater flow, creating a tortuous path that allowed a better transport within the membrane. The presence of clay also provided a higher yield, as the separation of the indigo blue presented $94.0 \%$ for the membranes containing $1 \%$ clay. Although the clay-containing membranes had a larger amount of fingers and macropores in the whole porous support, they obtained a larger amount of pores, but with smaller diameters than those contained in the PES membrane. Thus, it was possible to obtain a smaller permeate amount of indigo blue. Due to the average size of the indigo particles, the membranes may be attributed to the microfiltration characteristic. Therefore, it can be seen that the membranes have the advantages of high flow and greater rejection for the clay-containing membranes, but there is still a major challenge with regard to fouling of the polyethersulfone membrane.

Author Contributions: Conceptualization and methodology, R.d.S.B.F., H.d.L.L. and E.M.A.; Data curation, R.d.S.B.F., A.F.S., S.S.L.O. and V.d.N.M.; Formal analysis, R.d.S.B.F., A.F.S., S.S.L.O. and V.d.N.M.; Funding acquisition, E.M.A. and H.d.L.L.; Resources, E.M.A. and H.d.L.L.; Writing-original draft, R.d.S.B.F. and A.F.S.; Writing一review \& editing, R.d.S.B.F., A.F.S., E.M.A. and H.d.L.L.; Supervision, E.M.A. and H.d.L.L.

Funding: This research was financially assisted by MCTIC/CNPq: PNPD/CAPES and CAPES.

Acknowledgments: The authors thank to Bentonit União Nordeste (BUN) for the supply clay, MCTIC/CNPq, PNPD/CAPES and CAPES for financial assistance.

Conflicts of Interest: The authors declare no conflicts of interest. 


\section{References}

1. Xia, Q.C.; Liu, M.L.; Cao, X.L.; Wang, Y.; Xing, W.; Sun, S.P. Structure design and applications of dual-layer polymeric membranes. J. Membr. Sci. 2018, 562, 85-111. [CrossRef]

2. Farahani, M.H.D.A.; Rabiee, H.; Vatanpour, V. Comparing the effect of incorporation of various nanoparticulate on the performance and antifouling properties of polyethersulfone nanocomposite membranes. J. Water Process Eng. 2019, 27, 47-57. [CrossRef]

3. Liu, F.; Hashim, N.A.; Liu, Y.; Abed, M.R.M.; Li, K. Progress in the production and modification of PVDF membranes. J. Membr. Sci. 2011, 375, 1-27. [CrossRef]

4. Amaral, M.C.S.; Neta, L.S.F.; Souza, M.; Cerqueira, N.; Carvalho, R.B.D. Evaluation of operational parameters from a microfiltration system for indigo blue dye recovery from textile dye effluent. Desalin. Water Treat. 2014, 52, 257-266. [CrossRef]

5. Li, L.; Yan, G.; Wu, J.; Yu, X.; Guo, Q. Surface-initiated atom-transfer radical polymerization from polyethersulfone membranes and their use in antifouling. e-Polymers 2009, 9. [CrossRef]

6. $\mathrm{Xu}, \mathrm{W}$; Ge, Q. Synthetic polymer materials for forward osmosis (FO) membranes and FO applications: A review. Res. Chem. Eng. 2019, 35, 191-209. [CrossRef]

7. Goh, P.S.; Ong, C.S.; Ng, B.C.; Ismail, A.F. Nanotechnology in Water and Wastewater Treatment: Applications of Emerging Nanomaterials for Oily Wastewater Treatment; Elsevier: Amsterdam, The Netherlands, 2019.

8. Wu, G.; Gan, S.; Cui, L.; Xu, Y. Preparation and characterization of PES/TiO2 composite membranes. Appl. Surf. Sci. 2008, 254, 7080-7086. [CrossRef]

9. Shen, L.; Bian, X.; Lu, X.; Shi, L.; Liu, Z.; Chen, L.; Hou, Z.; Fan, K. Preparation and characterization of $\mathrm{ZnO} /$ polyethersulfone (PES) hybrid membranes. Desalination 2012, 293, 21-29. [CrossRef]

10. Razmjou, A.; Mansouri, J.; Chen, V. The effects of mechanical and chemical modification of $\mathrm{TiO}_{2}$ nanoparticles on the surface chemistry, structure and fouling performance of PES ultrafiltration membranes. J. Membr. Sci. 2011, 378, 73-84. [CrossRef]

11. Hosseini, S.A.; Vossoughi, M.; Mahmoodi, N.M.; Sadrzadeh, M. Clay-based electrospun nanofibrous membranes for colored wastewater treatment. Appl. Clay Sci. 2019, 168, 77-86. [CrossRef]

12. Simona, C.; Raluca, I.; Anita-Laura, R.; Andrei, S.; Raluca, S.; Bogdan, T.; Elvira, A.; Catalin-Ilie, S.; Claudiu, F.R.; Daniela, I.-E.; et al. Synthesis, characterization and efficiency of new organically modified montmorillonite polyethersulfone membranes for removal of zinc ions from wastewasters. Appl. Clay Sci. 2017, 137, 135-142. [CrossRef]

13. Mierzwa, J.C.; Arieta, V.; Verlage, M.; Carvalho, J.; Vecitis, C.D. Effect of clay nanoparticles on the structure and performance of polyethersulfone ultrafiltration membranes. Desalination 2013, 314, 147-158. [CrossRef]

14. ASTM. Standard Test Methods for Tensile Properties of Thin Plastic Sheeting. D 882. Annual Book of ASTM.; American Society for Testing and Materials: Philadelphia, PA, USA, 1992.

15. Ahmad, A.L.; Abdulkrim, A.A.; Shafie, Z.M.H.M.; Ooi, B.S. Fouling evaluation of PES/ZnO mixed matrix hollow fiber membrane. Desalination 2017, 403, 53-63. [CrossRef]

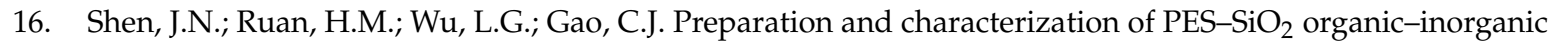
composite ultrafiltration membrane for raw water pretreatment. Chem. Eng. J. 2011, 168, 1272-1278. [CrossRef]

17. Leo, C.P.; Lee, W.C.; Ahmad, A.L.; Mohammad, A.W. Polysulfone membranes blended with ZnO nanoparticles for reducing fouling by oleic acid. Sep. Purif. Technol. 2012, 89, 51-56. [CrossRef]

18. Junaidi, N.F.D.; Othman, N.H.; Shahruddin, M.Z.; Alias, N.H.; Lau, W.J.; Ismail, A.F. Effect of graphene oxide (GO) and polyvinylpyrollidone (PVP) additives on the hydrophilicity of composite polyethersulfone (PES) membrane. Malays. J. Appl. Sci. 2019, 15, 361-366.

19. Ghaemi, N.; Madaeni, S.S.; Alizadeh, A.; Rajabi, H.; Daraei, P. Preparation, characterization and performance of polyethersulfone/organically modified montmorillonite nanocomposite membranes in removal of pesticides. J. Membr. Sci. 2011, 382, 135-147. [CrossRef]

20. Ferreira, R.S.B.; Pereira, C.H.Ó.; Paz, R.A.; Leite, A.M.D.; Araújo, E.M.; Lira, H.L. Influence of Processing Type in the Morphology of Membranes Obtained from PA6/MMT nanocomposites. Adv. Mater. Sci. Eng. 2014, 2014, 659148. [CrossRef] 
21. Rekik, S.B.; Gassara, S.; Bouaziz, J.; Deratani, A.; Baklouti, S. Enhancing hydrophilicity and permeation flux of chitosan/kaolin composite membranes by using polyethylene glycol as porogen. Appl. Clay Sci. 2019, 168, 312-323. [CrossRef]

22. Daraei, P.; Ghaemi, N. Synergistic effect of Cloisite 15A and 30B nanofillers on the characteristics of nanocomposite polyethersulfone membrane. Appl. Clay Sci. 2019, 172, 96-105. [CrossRef]

23. Rambabu, K.; Bharath, G.; Monash, P.; Velu, S.; Banat, F.; Naushad, M.; Arthanareeswaran, G.; Show, P.L. Effective treatment of dye polluted wastewater using nanoporous $\mathrm{CaCl}_{2}$ modified polyethersulfone membrane. Process Saf. Environ. 2019, 124, 266-278. [CrossRef]

24. Wang, X.L.; Qian, H.J.; Chen, L.J.; Lu, Z.Y.; Li, Z.S. Dissipative particle dynamics simulation on the polymer membrane formation by immersion precipitation. J. Membr. Sci. 2008, 311, 251-258. [CrossRef]

25. Ahmad, A.L.; Abdulkarim, A.A.; Ismail, S.; Ooi, B.S. Preparation and characterisation of PES-ZnO mixed matrix membranes for humic acid removal. Desalin. Water Treat. 2015, 54, 3257-3268. [CrossRef]

26. Rezaei, M.; Ismail, A.F.; Hashemifard, S.A.; Bakeri, G.; Matsuura, T. Experimental study on the performance and long-term stability of PVDF/montmorillonite hollow fiber mixed matrix membranes for CO2 separation process. Int. J. Greenh. Gas Con. 2014, 26, 147-157. [CrossRef]

27. Sotto, A.; Rashed, A.; Zhang, R.X.; Martínez, A.; Braken, L.; Luis, P.; Van der Bruggen, B. Improved membrane structures for seawater desalination by studying the influence of sublayers. Desalination 2012, 287, 317-325. [CrossRef]

28. Yeh, J.M.; Yu, M.Y.; Liou, S.J. Dehydration of water-alcohol mixtures by vapor permeation through PVA/clay nanocomposite membrane. J. Appl. Polym. Sci. 2003, 89, 3632-3638. [CrossRef]

29. Zhang, Y.; Wang, R. Novel method for incorporating hydrophobic silica nanoparticles on polyetherimide hollow fiber membranes for $\mathrm{CO}_{2}$ absorption in a gas-liquid membrane contactor. J. Membr. Sci. 2014, 452, 379-389. [CrossRef]

30. Ghalamchi, L.; Aber, S.; Vatanpour, V.; Kian, M. A novel antibacterial mixed matrixed PES membrane fabricated from embedding aminated $\mathrm{Ag}_{3} \mathrm{PO}_{4} / \mathrm{g}-\mathrm{C} 3 \mathrm{~N} 4$ nanocomposite for use in the membrane bioreactor. J. Ind. Eng. Chem. 2019, 70, 412-426. [CrossRef]

31. Ismail, N.M.; Ismail, A.F.; Mustafa, A.; Matsuura, T.; Soga, T.; Nagata, K.; Asaka, T. Qualitative and quantitative analysis of intercalated and exfoliated silicate layers in asymmetric polyethersulfone/cloisite15A®mixed matrix membrane for $\mathrm{CO}_{2} / \mathrm{CH}_{4}$ separation. Chem. Eng. J. 2015, 268, 371-383. [CrossRef]

32. Azeez, A.A.; Rhee, K.Y.; Park, S.J.; Hui, D. Epoxy clay nanocomposites-processing, properties and applications: A review. Compos. Part B Eng. 2013, 45, 308-320. [CrossRef]

33. Muhamad, M.S.; Salim, M.R.; Lau, W.J. Surface modification of $\mathrm{SiO}_{2}$ nanoparticles and its impact on the properties of PES-based hollow fiber membrane. RSC Adv. 2015, 5, 58644-58654. [CrossRef]

34. Ferreira, R.S.B.; Oliveira, S.S.L.; Salviano, A.F.; Araújo, E.M.; Leite, A.M.D.; Lira, H.L. Polyethersulfone Hollow Fiber Membranes Developed for Oily Emulsion Treatment. Mater. Res. 2019, 22, 1-8. [CrossRef]

35. Gao, J.; Thong, Z.; Wang, K.Y.; Chung, T.S. Fabrication of loose inner-selective polyethersulfone (PES) hollow fibers by one-step spinning process for nanofiltration (NF) of textile dyes. J. Membr. Sci. 2017, 541, 413-424. [CrossRef]

36. Lima, R.C.O.; Lira, H.L.; Neves, G.A.; Silva, M.C.; França, K.B. Use of ceramic membrane for indigo separation in effluent from textile industry. Mater. Sci. Forum 2014, 789, 537-541. [CrossRef]

(C) 2019 by the authors. Licensee MDPI, Basel, Switzerland. This article is an open access article distributed under the terms and conditions of the Creative Commons Attribution (CC BY) license (http://creativecommons.org/licenses/by/4.0/). 